\title{
IDENTIDADE RACIAL E IDENTIFICAÇÃO RACIAL $^{1}$
}

\author{
Kwame Anthony Appiah \\ Tradução por Gizele dos Santos Belmon ${ }^{2}$
}

(...)

Se nós seguirmos o distintivo de cor de "Africano para "Negro" para "raça colorida" para "black" para "afro-americano" (e isto ignora tão fascinante desvio como a fuga em direção ao "afro-saxon") nós estamos deste modo, traçando a história não somente de um significante, um rótulo, mas também uma história de seus efeitos. A qualquer momento nesta história houve, entre as colônias americanas e os Estados Unidos que o sucederam, um sólido consenso entre aqueles rotulados negros (Black) e aqueles rotulados brancos(White), como para quem, em suas próprias comunidades, se sentiram sob as ordens a que rotulam. (Como ocorreu na imigração da China e outras partes do "Extremo Oriente", uma rotulação oriental veio ter igual estabilidade). Houve, sem dúvida, algum "passing"; mas o conceito de passing implica que, se o fato relevante sobre o ancestral destes indivíduos tinham se tornado conhecido, a maioria das pessoas os teriam levado para estar viajando sob o distintivo errado.

A maior exceção norte americana foi em Louisiana (sul), onde um diferente sistema em que um grupo intermediário crioulo, nem branco nem negro, tinha reconhecimento social; mas Plessy Fergusson refletiu a extensão a qual Louisiana Purchase trouxe efetivamente mesmo que gradualmente aquele estado para dentro da tendência americana de classificação racial. Neste caso, Homer Adolph Plessy - um crioulo gentleman que poderia certamente ter passado na maioria dos lugares por branco - descobriu em 1896, depois de um longo processo de apelo, que a Suprema Corte dos Estados Unidos propôs tratá-lo como um Negro e portanto, reconhecer o direito do Estado da Louisiana de mantê-lo a si mesmo e os seus concidadãos brancos "separados mas iguais".

O resultado é que há pelo menos três objetos socioculturais na América negros, brancos e orientais - cujo pertencimento (membership) em qualquer época é relativamente e ainda cada vez mais determinante. Estes objetos são históricos neste sentido: para identificar ao longo do tempo todos os membros destas raças americanas, você não pode procurar um único critério que aplica-se sempre igualdade; você pode encontrar o ponto de partida pela raça - a fonte subcontinental de uma população de indivíduos que define seu pertencimento inicial - e então aplicar em cada momento histórico o critério de continuidade inter-temporal que aplica naquele momento de decidir quais indivíduos na próxima geração contam

\footnotetext{
${ }^{1}$ Artigo de Kwame Anthony Appiah. Racial Identity and Racial Identification. In: Back, L.; SOLOMOS, J.(eds). Theories of race and racism. A reader. London: /New York: Routhledge,2000, pp. 606-615.

${ }^{2}$ Graduada em História pela Universidade Estadual de Feira de Santana (UEFS), Feira de Santana, Bahia - Brasil. E-mail: filha21@yahoo.com.br
} 
como pertencentes ao grupo. Há desde o início até o presente, no coração do sistema, uma simples regra que exatamente poucos disputariam até hoje: onde ambos os pais são de uma única raça, a criança é de uma mesma raça que os pais.

$\mathrm{O}$ critério aplicável em qualquer época pode deixar vagas fronteiras. Eles certamente mudam como as várias decisões sobre qual proporção do ancestral africano fez o negro ou a incerteza atual como para nomear as crianças de "miscigenação" branca-amarela demonstra. Mas eles definitivamente sempre nomeiam algumas pessoas para o grupo e definitivamente expulsam outras; e para a maior parte da história da América a classe de pessoas sobre quem houve incerteza (são a Flórida seminoles negra ou indiana?) era relativamente pequena.1

Uma vez que o rótulo racial é aplicado à pessoa, ideias sobre a que ela se refere, ideias que podem ser muito menos consensual do que as aplicações do rótulo tem seus efeitos sociais. Mas eles não tem só efeitos sociais, mas também psicológicos; e eles moldam a maneira como as pessoas concebem a si mesmas e seus projetos. Em particular, os rótulos podem operar para moldar o que eu quero chamar de "identificação": o processo através do qual um indivíduo intencionalmente constrói seus projetos - incluindo seus planos para sua própria vida e sua concepção de bom - pela referência aos rótulos disponíveis, identidades disponíveis.

Identificação é central para o que Ian Hacking tem chamado de "perfazendo pessoas"2. Delineando um número de exemplos, mas centralmente homossexualidade e síndrome da múltipla personalidade. Ele defende o que ele chama um "normalismo dinâmico", pelo qual argumenta que "numerosos tipos de seres humanos e ações humanas chegam mão a mão (hand in hand) com nossa invenção das categorias rotulando-os." $3 \mathrm{Eu}$ apenas tenho articulado um normalismo dinâmico sobre um tipo de pessoa que é atualmente chamada "africano-americano".

Hacking nos faz lembrar do truísmo psicológico, cuja maior influência está no trabalho sobre intenção de Elizabeth Anscombe, que em ação intencional as pessoas agem "sob adscrições"; que suas ações são conceitualmente moldadas. Daí decorre, é claro, que o que as pessoas podem fazer depende de quais conceitos elas tem disponível para elas; e entre os conceitos que podem moldar as ações de alguém é o conceito de um certo tipo de pessoa e o comportamento apropriado para aquele tipo.

Hacking oferece como um exemplo a evocação magnífica de Sartre, em Being and Nothingness, de Persian Garçon de café: "Seu movimento é rápido e direto, um pouco mais preciso, um pouco rápido. Ele vem em direção ao patrão com um passo um pouco mais rápido. Ele curva um pouco ansioso também, seus olhos manifestam interesse muito solícito por uma ordem do cliente". 4 Hacking comenta: 


\begin{abstract}
"O anti herói de Sartre escolheu ser um garçon. Evidentemente que não foi uma escolha possível em outros lugares, outras épocas. Há pessoas servis na maioria das sociedades, e empregada doméstica em muitas, mas um garçon é algo específico, e um garçon de café mais específico...

Como em quase todas as formas em que é possível ser uma pessoa, é possível ser um garçon de café somente numa certa época, e num certo lugar, num certo grupo social. O servo feudal que coloca comida sobre a minha mesa nobre não pode mais escolher ser um garçon de café que ele pode escolher ser lord da cãs senhorial. Mas, a impossibilidade é evidentemente do tipo diferente. 5
\end{abstract}

A ideia de garçon de café carece, até agora como eu pude ver, de uma sorte de compromisso teórico que são trilhados pela ideia do negro e branco, o homossexual e o heterossexual. Então não faz sentido perguntar a alguém que tem um emprego como um garçon de café se aquilo é o que ele realmente é. $\mathrm{O}$ ponto não é que nós não temos expectativas do garçon de café: porque ele é uma identidade reconhecível. É preferível que aquelas expectativas sejam sobre a performance da função; eles dependem da nossa suposição de conformidade intencional para aquelas expectativas. Como eu gasto algum tempo argumentando anteriormente, nós podemos perguntar se alguém é realmente da raça negra, porque a constituição dessa identidade é geralmente comprometida teoricamente: nós esperamos que as pessoas de uma certa raça comportem-se de um certo modo não simplesmente porque elas estão em conformidade com o script daquela identidade, executando aquele papel, mas porque elas têm certo antecedente de propriedades que são conseqüências da apropriação do rótulo aplicado a elas. Isto porque a adscrição das identidades raciais - o processo de aplicação do rótulo às pessoas, incluindo nós mesmos - é baseado sobre mais do que intencional identificação que pode ser uma brecha entre o que uma pessoa adscritivamente é e a identidade racial que ele desempenha: esta é uma brecha que faz o passing possível.

A raça é deste modo, como todas as principais formas de identificação que são centrais para a identidade política contemporânea: feminino e masculino; gay, lésbica, heterossexual; negro, branco, amarelo, vermelho e marrom; judaico, japonês, e koreano-americano; mesmo a mais negligenciada das identidades americana, classe. Há em todos eles um conjunto de critérios por adscrição comprometidos teoricamente, nem todos do qual são assegurados por todos, e o qual podem não ser consistentes uns com os outros assim na 
adscrição de uma única pessoa; e há então um processo de identificação no qual o rótulo molda as ações intencionais daqueles que lhe estão sujeitos.

Daí não decorre do fato da identificação moldar a ação, moldar os planos da vida, que a identificação ela mesma pode ser pensada como voluntária. Eu nunca recordo de escolher a identidade com um masculino; 6 mas ser masculino tem moldado muito dos meus planos e ações. De fato, onde minha adscrição de identidade é uma sobre a qual quase todos os meus companheiros cidadãos concordam, eu provavelmente tenho pouco sentido de escolha sobre se a identidade é minha; embora eu possa escolher como central minha identificação com ele será - escolha, que é, quanto eu organizarei minha vida em torno daquela identidade. Desse modo, se eu estou entre aqueles (como infelizmente rotulado "heterossexual- acting gay men" ou a maioria de judeus americanos) que são capazes de, se eles escolhessem, escapar a adscrição, eu posso escolher não seguir uma identidade gay ou judia; embora isto requererá ocultação de fatos sobre mim mesmo ou meu ancestral de outros.

$\mathrm{Se}$, de um lado, eu me enquadro na classe daqueles cujo consenso sobre a adscrição não está claro - como entre comtemporaneamente chamados biracials, ou bissexuais, aqueles muitos americanos brancos de múltiplas heranças 7 étnicas identificáveis - eu posso ter um sentido de opções de identidade: mas um modo é que eu posso exercê-las marcando a mim mesmo etnicamente (como quando alguém escolhe vestir um broche irlandês) de forma que os outros terão então mais provavelmente que adscrever aquela identidade para mim.

\section{Diferenças entre Diferenças}

Identidades coletivas diferem, é claro, em muitos modos; o corpo é central para raça, gênero, e sexualidade, mas não tão central para classe e etinicidade. E, para repetir um ponto importante, identificação racial é simplesmente mais difícil resistir do que identificação étnica. A razão é dupla. Primeiro adscrição racial é mais saliente socialmente: a menos que você seja morfologicamente atípico para seu grupo racial, estrangeiros, amigos, oficiais estão sempre a par do contexto público e privado, sempre o nota, quase nunca deixa escapar à vista. Segundo - e novamente ambos os grupos privados e em espaço público - raça é levada por muitas pessoas para ser a base por tratamento diferenciado das pessoas, (neste aspecto, a identidade judia na América aparece para mim como sendo um longo caminho em direção à identidade africana-americana: há modos de falar e agir e olhar - e importa 
muito pouco se eles são "realmente" mais cultural ou mais genético - que são associados com ser judeu; e há muitas pessoas, brancas e negras, judeus e gentile, de quem esta identidade é força central em moldar suas respostas para os outros.)

Dentre muito sobre identificação disse, nós podemos ver que o problema analítico de Du Bois era, em conseqüência, que ele acreditava que por rotulação racial desta sorte para ter um efeito real obvio que eles tiveram entre eles, crucialmente, sua própria identificação com outras pessoas negras e com a África - lá deve haver alguma essência real que manteve a raça unida. Nossa consideração da história do rótulo revela que isto é um erro: uma vez que focamos, como Du Bois quase viu sobre o distintivo de raça - o significante preferivelmente do que o significado, a palavra preferivelmente do que o conceito - nós vemos que ambos os efeitos da rotulação são poderosos e reais e que falsas ideias, confusão, erro e prejuízo, desempenharam um papel central na determinação de ambos como o rótulo foi aplicado e o que propõe.

Isto, acredito, é porque Du Bois tão frequentemente encontrou a si mesmo reduzido, em sua tentativa de definir raça, oculta forças: se você olha por uma essência partilhada você não conseguirá nada, então você virá acreditar que você o tem perdido, porque é super-sutil, dificulta a experiência ou identifica: em resumo, misterioso. Mas, se como eu disse, você entende o processo sócio-histórico de construção da raça você verá que o rótulo trabalha apesar da ausência de uma essência.

Talvez, então, nós possamos permitir que o que Du Bois era depois era a ideia da identidade racial, pelo qual eu devo definir aproximadamente como um rótulo, $\mathrm{R}$, associado com adscrições pela maioria das pessoas (onde a adscrição envolve critérios descritivos por aplicação do rótulo); e identificações por aqueles que estão fora do âmbito (onde identificação implica um papel modular pelo rótulo numa ação intencional dos possuidores, tanto que eles algumas vezes agem como um R), onde há uma história de possuidores associados do rótulo com uma essência racial inerente (mesmo se alguém que use o rótulo não mais acredita na essência racial).

De fato, nós devemos argumentar que identidades raciais poderiam persistir mesmo se ninguém acreditava na essência da raça, providas ambas adscrição e contínua identificação.

Haverá alguém que opor-se-á a minha consideração que não dar ao racismo um lugar central na definição de identidade racial: isto é obvio, penso, da história eu tenho explorado que o racismo tem sido central para $o$ desenvolvimento da teoria de raça. Em que sentido racismo tem sido parte da 
história ao longo do tempo. Mas você pode dar uma consideração de identidade racial pelo qual você não considerou nada como uma essência racial a menos que isto implicasse uma hierarquia entre as raças; 8 ou a menos que o rótulo desempenhasse um papel na prática racista. Eu tenho alguma simpatia com a estratégia anterior; apropriado facilmente no meu quadro básico. A última estratégia, contudo, eu faço a objeção do filósofo que confunde prioridade lógica e causal: não tenho dúvida que as teorias raciais cresceram, em parte, como racionalizações por maltratar negros, judeus, chineses, e vários outros. Mas penso que é útil reservar o conceito de racismo, como oposto ao etnocentrismo ou simplesmente desumanidade, para práticas na qual um conceito de raça desempenha um papel central. E eu duvido que você possa explicar o racismo sem primeiro explicar o conceito de raça.

Eu estou solidário, contudo, com um animado impulso atrasado de tais propostas, que é a certeza de que aqui na América nós não temos discussões de raça no qual racismo desaparece à vista. Como pontuamos, identificação racial é difícil de resistir em parte porque a adscrição racial por outros é muito insistente; e seus efeitos - especialmente, mas não por significar exclusivamente, o racista - são tão difíceis para escapar. Isto é obvio, penso que a persistência do racismo significa que adscrição racial tem conseqüências negativas para alguns e consequiências positivas para outros - criando, em particular, o privilégio da pele-branca que é tão fácil para as pessoas que tendem a esquecer; e é claro, também, que para aqueles que sofrem das conseqüências negativas, a identificação racial é uma resposta previsível, especialmente onde o projeto sugere é que as vítimas do racismo deveriam se unir para resisti-lo. Eu devo retornar mais tarde para algumas das importantes consequências morais do presente racismo e o legado do racismo do passado.

Mas, antes de fazê-lo quero oferecer alguma base para a preferência da consideração da identidade racial que eu propus, pelo qual lugares da essência racial ocupa o centro sobre a mais nova consideração que vê a identidade racial como uma espécie de cultura de identidade.

(...) Nos Estados Unidos, não só étnico, mas fronteiras raciais são culturalmente marcadas. Em White Women, Race Matters: The Social Construction of Whitness,9 Ruth Frankenberg recorda a ansiedade de muitas mulheres brancas que não veem a si mesmas como brancas "étnicas" e preocupa portanto, que elas não tenham cultura.10 Isto é um pouco intrigante na vida da pessoa, como cada ser humano normal faz, em ricas estruturas de conhecimento, experiência, valores e significados; trouxe gostos e práticas: esta perplexidade, em resumo, na pessoa com vida humana normal. Mas, a 
razão destas mulheres não reconhecerem que elas têm uma cultura é porque nenhuma destas coisas que, atualmente, fazem suas vidas culturais são marcadas como branca, como pertencimento especialmente para elas: e as coisas que são marcadas como branco(racismo, privilégio branco) são coisas que elas querem repudiar. Muitos africano-americanos, por outro lado, tem a vida cultural na qual o modo que eles comem, a igreja que eles freqüentam, a música que eles escutam, e o modo como falam são marcados como negro: suas identidades são marcadas por diferenças culturais.

Tenho insistido que africano-americanos não tem uma cultura única, no sentido de linguagem, valores, práticas e significados partilhados. Mas, muitas pessoas que pensam a raça como grupo definido por culturas partilhadas, concebem que são partilhadas de modos diferentes. Eles compreendem as pessoas negras como compartilhamento de cultura negra por definição: jazz ou hip hop pertence um africano-americano, se elas gostam ou sabem alguma coisa sobre ele porque ele é culturalmente marcado como negro. Jazz pertence a uma pessoa negra que não sabe nada sobre o assunto mais plenamente ou naturalmente que ele faz para um branco jazzman (...).

\section{Identidade e Normas}

Tenho explorado estas questões sobre cultura em ordem para mostrar quão insatisfatória uma consideração do significado de raça que confunde identidade e cultura. Mas, este é um erro que expulsa da identidade interesse moral e político, há um melhor caminho?

Precisamos voltar para análise da identidade racial. Enquanto as teorias sob a qual a adscrição é baseada não na necessidade deles mesmos serem normativos, estas identidades vêm com normativas tanto quanto expectativa descrição; sobre o qual, uma vez mais, pode haver ambos inconsistência no pensamento do indivíduo e razoavelmente difundida discordância entre eles. Há, por exemplo, uma extensão de opiniões entre judeus americanos como o que eles sendo judeus o comprometem; e enquanto a maioria gentile provavelmente não pensa muito sobre o problema, pessoas com freqüência fazem observações que sugerem que eles admirem o modo no qual, como eles acreditam judeus tem "uma admiração que parece que pressupõe a ideia de moral que é se não moralmente obrigatória, então pelo menos, moralmente desejável, por aqueles que partilham identidades levam responsabilidade uns para com os outros. (comentário similar tem sido feito com muita freqüência sobre coreanos-americanos.) 
Nós precisamos, em síntese, ser claros que a relação entre identidades e vida moral é complexa. Na tradição liberal, a qual eu aderi, nós vemos a moralidade pública como empenho de cada um de nós como indivíduo com nossa "identidade" individual: e temos a noção, que vem (como Charles Taylor tem certamente argumentado) da autenticidade ética, que, outras coisas sendo iguais, as pessoas têm o direito de ser admitida publicamente como o que eles realmente já são. Isto porque alguém já é autenticamente judeu ou gay que nós o negamos alguma coisa em requerimento deles para esconder este fato, para "pass", como dissemos, por alguma coisa que eles não são. Charles Taylor tem sugerido que nós chamemos o assunto político erguido por este fato a política de reconhecimento: uma política que nos questiona para a admissão socialmente e politicamente da identidade autêntica de outros.

Como tem sido pontuado com freqüência, contudo, o caminho da discussão de reconhecimento procede é estranhamente na vantagem com o impulso individualista de conversas de autenticidade e identidade. Se o que importa sobre mim é o meu eu individual e autêntico, por que então muitas conversas contemporâneas de identidade sobre uma vasta categoria - raça, gênero, etnicidade, nacionalidade, sexualidade - que parece tão longe do indivíduo? Qual é a relação entre estas linguagens coletivas e o impulso individualista da noção moderna do eu? Como a vida social tem chegado a ser tão limitada com uma ideia de identidade que tem profundas raízes num romantismo com esta celebração do individual sobre e contra a sociedade?

A conexão entre identidade individual de um lado, e raça e outras identidades coletivas, de outro, parece ser algo como isto: cada identidade individual da pessoa é vista como tendo duas dimensões maiores. Há uma dimensão coletiva, a intersecção das identidades coletivas: e há o que eu chamarei uma dimensão pessoal, consistindo de outras feições da pessoa socialmente e moralmente importante - inteligência, charme, razão, - que não são elas mesmas as bases e formato da identidade coletiva.

A distinção entre estas duas dimensões de identidade é, só para falar, mais uma distinção sociológica do que uma distinção lógica. Em cada dimensão nós estamos falando sobre propriedades que são importantes para a vida social. Mas somente as identidades coletivas consideram como categorias sociais, tipos de pessoas. Há uma categoria lógica, mas não categoria social do satírico, ou inteligente, ou encanto, ou ganancioso: pessoas que partilham estas propriedades não constituem um grupo social, num sentido relevante. $O$ conceito de autenticidade é central para a conexão entre estas duas dimensões; e há um problema em muitas compreensões atuais daquela relação, uma má 
compreensão pode-se encontrar, por exemplo, no recente ensaio (brilhante) de Chrarles Taylor Multiculturalism and the Politcs of Recognition (...)

\section{Além da Identidade}

Grande parte das identidades coletivas que clamam por reconhecimento vem com noções de tipo de comportamento da própria pessoa: não é que há um modo que as pessoas negras deveriam comportar-se, mas que há modos de comportamento próprio do negro. Estas noções provêm de normas e modelos frouxos, que desempenham um papel moldando os planos da vida daqueles que fazem estas identidades coletivas central para as suas identidades pessoais; das identificações daqueles que voam sob este estandarte. 13 Identidades coletivas, em síntese, prover o que nós podemos chamar script: narrativas que as pessoas podem usar moldando seus planos de vida e contando suas histórias de vida. Em nossa sociedade (embora não, talvez, na Inglaterra de Addison e Steele) sendo satírico neste modo não sugere uma vida script de "razão". E isto porque o que eu chamei de dimensões pessoais de identidade trabalham diferentemente da coletiva.

Este ponto não é somente sobre o ocidente moderno: o cruzamento cultural (cross-culturally) importa para as pessoas cujas vidas tenham certa unidade narrativa; eles querem ser capazes de contar uma estória de suas vidas que fazem sentido. A história (story) - minha estória - cohere no caminho apropriado pelo padrão feito disponível na minha cultura para uma pessoa de minha identidade. Conta que a estória, como uma adaptação na história(story) mais ampla de várias coletividades é , para a maioria de nós, importante. Isto não apenas na identidade de gênero que molda a vida (através, por exemplo, de rituais de passagem da mulher - ou masculinidade): identidade étnica e nacional também adapta cada história (story) individual no interior de uma narrativa ampla. E alguns dos "indivíduos" mais individualistas valorizam tais coisas. Hobbes falou que o desejo por glória como um dos impulsos que dominam os seres humanos, que foi destinado para criar problema para vida social. Ma a glória pode consistir em adapta-se e ser visto como inserido numa história coletiva: e então, em nome da glória, pode-se acabar fazendo as coisas mais sociais de todas.

Como esta ideia geral aplica para nossa situação corrente no ocidente multicultural? Vivemos em sociedades em que certos indivíduos não tem sido tratados com igual dignidade porque eles foram, por exemplo, mulheres, homossexuais, negros, católicos. Porque, como Taylor tão persuasivamente 
argumenta, nossas identidades são dialogicamente moldadas, pessoas que tem estas características central - com freqüência, negativamente central - para suas identidades. Atualmente há um consentimento muito difundido que os insultos para sua dignidade e as limitações de sua autonomia imposta em nome das identidades coletivas são seriamente errôneas. Uma forma de cicatrização do eu que aqueles que tem estas identidades participam é aprender a ver estas identidades coletivas não como fonte de limitação e insulto mas como uma valiosa parte do que eles centralmente são. Porque a ética e autenticidade requer de nós expressar o que nós centralmente somos em nossas vidas, eles movem próximo a demanda que eles serão reconhecidos na vida social como mulheres, homossexuais, negros, católicos. Porque não houve razão para maltratar as pessoas desta sorte, e porque a cultura continua a prover imagens degradadas deles não obstante, eles demandam que nós façamos um trabalho cultural para resistir os estereótipos, para desafiar os insultos, para retirar as restrições.

Estas velhas restrições sugeriram script da vida por portadores destas identidades, mas elas são negativas. Nesta ordem para construir a vida com dignidade, parece natural levar a identidade coletiva e construir scripts positivos da vida.

Um africano-americano depois do Movimento Black Power leva o velho script da auto-aversão, o script no qual ele ou ela é um nigger, e trabalha em comunidade com outros, para construir um série de script da vida negra positiva. Nesta vida script, ser um negro é recodificado como ser black: e isto requer, entre outras coisas, recusa para assimilar as normas e comportamento do discurso branco. E se é para ser negro numa sociedade que é racista então se tem que negociar constantemente com os ataques sobre a dignidade. Neste contexto, insistindo sobre o direito de viver uma vida digna não será o bastante. Não será o bastante requerer ser tratado com igualdade e dignidade apesar de ser negro: pelo que será requerido uma concessão que sendo negro, considera naturalmente ou alguma condição contra a dignidade. E então, acabará pedindo para ser respeitado como um negro.

Eu espero que pareça simpático a esta história(story). Eu sou simpático. Eu vejo como a história(story) acontece. Isto deve ser mesmo historicamente, estrategicamente necessário para a história(story) ir neste caminho.14 Mas eu penso que nós precisamos dar o próximo passo necessário, que é perguntar se as identidades construídas deste modo são únicas todos nós podemos ser felizes com uma corrida mais longa. Qual demanda respeita as pessoas como negras ou como gays requer que haja algum script que vá com ser um afro-americano 
ou ter algum desejo sexual respectivamente. Há de prover modos de ser negro e ser gay: haverá expectativas de ser encontrado; demandas serão feitas. Neste ponto, alguém que leva autonomia seriamente vai querer perguntar se nós não temos que substituir um tipo de tirania por outra. Se eu tinha que escolher entre Uncle Tom e Black Power, eu deveria, é claro, escolher o último. Mas eu não gostaria de ter que escolher. Eu gostaria de outras opções. A política de reconhecimento que requer uma cor de pele, um corpo sexual, deveria ser politicamente admitida no modo que o faz tão severo para aqueles que querem tratar sua pele e seu corpo sexual como dimensões pessoais do seu eu. E "pessoal" não significa "secreto" mas "não também firmemente escrito, "também não constrangido pelas demandas e expectativas de outros".

Em síntese, então parece-me que aqueles que veem potencialidade pelo conflito entre liberdade individual e políticas de identidade estão corretos(rights). (...) 


\section{Notas e Referências}

1. Ver Kevin Mulroy, Freedon on the Border: the The Seminole Maroons in Florida, the Indian Territory, Coohuila, and Texas (Lubbock, Tex: Texas Tech University Press, 1993).

2. Ian Hacking, "Making Up People" reimpresso de Reconstructing Individualism: Autonomy, Individuality and the Self in Western Thought, ed. Thomas Heller, Morton Sousa, and David Wellbery (Stanford University Press, 1986), in Forms of Desire: Sexual Orientation and the Social Constructionist Controversy, ed. Edward Stein (New York: Routledge, 1992). pp. 69-88 (page references are to this version).

3. Hacking, "Making Up People", p.87.

4. Citado em ibid, p.81.

5. Ibid., p. 82.

6. Que eu não me lembro e não provo que eu não lembro, é claro.

7. Ver Mary C. Waters, Ethnic Opitions: Choosing Identities in America (Berkeley and Los Angeles: University of California Press, 1990).

8. Esta é a proposta do papel sobre racismo metafísico por Berel Lang at the New School for Social Research seminar "Race and Philosophy" in October 1994, do qual eu aprendi muito.

9. Ruth Frankenberg, White Women, Race Matters: The Social Construction of Whitness (Minneapolis: University of Minnesota Press, 1993).

10. A discussão deste trabalho é construída pela conversação com Larry Blum, Martha Minov, David Wilkins, and David Wong.

11. Chaerles Taylor. Multiculturalism and "The Politics of Recognition." Com comentário por Amy Gutmann, ed., K. Anthony Appiah, Jurgen Habermas, Steven C. Rockefeller, Michael Walzer, and Susan Wolf (Princeton: Princeton University Press, 1994).

12. Taylor nos faz lembrar corretamente da profunda contribuição de Trilling para nosso entendimento desta história, eu discuto o trabalho de Trilling no capítulo 4 em My Father's House.

13. Eu disse "Faça" aqui não porque penso que há sempre atenção consciente para a construção dos planos da vida ou experiência substancial da escolha porque eu quero enfatizar o ponto antiessencialista que há escolhas que podem ser feitas.

14. Compare o que Sartre escreveu em seu "Orphée Noir," in Anthologle de La Nouvelle Poésie Nègre et Malagache de Langue Française, ed. L. S. Senghor, p.xiv. Sartre argumentou, de fato, que este mover é o passo necessário na 
http://www.ufrb.edu.br/griot

progressão dialética. Nesta passagem ele argumenta explicitamente que o que ele chama de um "racismo antirracista" é um caminho para a unidade final... a abolição das diferenças de raça." 